\title{
THROMBOLYTIC THERAPY IN STEMI- RELEVANCE IN CURRENT WORLD OF INTERVENTIONAL CARDIOLOGY
}

\author{
K. Prabhakaran ${ }^{1}$, P. K. Mukandan²
}

${ }_{1}^{1}$ Associate Professor, Department of Medicine, Pariyaram Medical College, Pariyaram, Kannur.

${ }^{2}$ Associate Professor, Department of Medicine, Pariyaram Medical College, Pariyaram, Kannur.

\section{BACKGROUND}

\section{ABSTRACT}

Coronary artery disease is one of the most common non-communicable diseases in India, and acute myocardial infarction has been a leading cause of sudden death in many rural populations in a developing country like ours, where Cath Lab facilities are scarce.

Thrombolytic therapy was a major interventional landmark in treatment of STEMI in such resource-crunched settings before the year 2000 .

\section{MATERIALS AND METHODS}

In this retrospective observational study, 120 cases of STEMI, treated with thrombolysis in a health care centre in rural part of northern Kerala, during the period of 15 years from 1991-2004, when Interventional Cardiology wasn't popular, were studied.

\section{RESULTS}

It was noticed that 60 patients went on to survive on medical management alone, 30 required PTCA later in life and 10 required CABG later in life.

\section{CONCLUSION}

We conclude that thrombolytic therapy hasn't still lost its importance in a resource-crunched setting where Cath Lab facilities and coronary interventions are still not easily available.

\section{KEYWORDS}

Coronary Artery Disease, STEMI, Thrombolysis, Coronary Intervention, Developing Countries.

HOW TO CITE THIS ARTICLE: Prabhakaran K, Mukandan PK. Thrombolytic therapy in STEMI- Relevance in current world of Interventional Cardiology. J. Evolution Med. Dent. Sci. 2018;7(02):181-182, DOI: 10.14260/jemds/2018/40

\section{BACKGROUND}

Coronary Artery Disease (CAD) is one of the most common non-communicable diseases in India and one of its severe complications is Acute myocardial infarction- ST elevation MI (STEMI).(1)

The rate of increase of cardiovascular diseases in developing countries is almost double in comparison with developed countries. 52\% deaths due to CVD in India occur before 70 years of age. Primary coronary intervention is the preferred treatment for STEMI and requires expertise and adequate technology and financial resources. In absence of Cath Lab facilities, thrombolysis was the best available treatment option in cases of STEMI, and was practised widespread in many areas of our country. $(2,3)$

The longterm outcome of the patients undergoing thrombolysis were followed up in this study and was analysed to determine the efficacy of drug therapy in treatment and prevention of further complications of coronary artery disease.

'Financial or Other Competing Interest': None.

Submission 21-11-2017, Peer Review 21-12-2017,

Acceptance 27-12-2017, Published 08-01-2018.

Corresponding Author:

Dr. K. Prabhakaran

Associate Professor,

Department of Medicine,

Pariyaram of Medical Sciences,

Pariyaram,

Kannur-670503.

E-mail: k.prabhakaran36@yahoo.com

DOI: $10.14260 /$ jemds $/ 2018 / 40$

\section{MATERIALS AND METHODS}

This retrospective observational study was conducted in a secondary care centre with no Cath Lab facilities, in Wandoora village in rural part of Malappuram, a district of northern Kerala. 120 cases of STEMI who presented to the Medicine casualty who were treated with thrombolysis for during the period from January 1991 to January 2005 were followed up and the longterm outcome in each of the patients were studied.

\section{Inclusion Criteria}

All patients who presented with or without typical cardiac chest pain, who were found to have ECG changes consistent with ST elevation MI, and who had elevated cardiac enzymes (CK-MB: the only available cardiac biomarker in the centre at that time).

\section{Exclusion Criteria}

Patients with normal cardiac enzymes and non-specific ECG changes, or elevated cardiac enzymes but with features of nonST elevation MI or unstable angina.

The longterm outcome was determined by the number of patients who required coronary intervention strategies in the future including bypass grafting, patients who were uneventful after the initial event and continuing on antiplatelets, statins and lifestyle modifications alone, and patients who succumbed to CAD-associated complications.

\section{RESULTS}

Out of the 120 patients who were included in the study, $40 \%$ (48) were diabetic, $20 \%$ were hypertensive, $20 \%$ had both diabetes and hypertension, $20 \%$ were heavy smokers. The 
clinical success of thrombolysis with streptokinase was $90 \%$, two cases required thrombolysis with urokinase, as they were undergoing thrombolysis $2^{\text {nd }}$ time, suspecting antibodies. All the cases presented during the window period of 6 hours and majority came within first 2-3 hours. $90 \%$ of the cases had symptomatic relief from angina pain with fibrinolytic therapy. Reperfusion arrhythmias were noticed in $5 \%$ of the total cases. 4 patients had internal bleeding following thrombolysis which was managed conservatively and was stabilised, and one patient had intracerebral bleeding which was also stabilised. 16 patients required intravenous magnesium sulphate infusions to control arrhythmias. There was no mortality associated with the therapy or during the period after therapy.

On long term followup over the past 15 years, it was noticed that 10 patients who received thrombolytic therapy required CABG, and 30 patients required PTCA later in life. 20 patients were lost to followup, among which 8 died due to CAD-associated complications. 60 patients who have had strict adherence to the lifestyle modifications and antiplatelet therapy have survived with minimum CAD-related complications, none requiring any emergency interventions till date. These patients are still on thrice monthly followup. Dyslipidaemia, even though present in many of the patients wasn't found to be a determinant in the outcome.

\section{DISCUSSION}

Acute myocardial infarction and its complications are leading causes of mortality. Early coronary intervention is required in indicated cases for better survival and reduction of morbidity. In resource-crunched settings like rural India, where Cath Lab facilities are scarce, thrombolytic therapy is still an important part of the early treatment of STEMI. $(2,3,4)$ The advent of percutaneous intervention strategies and advance of bypass graft surgeries has made thrombolysis a very rarely done therapy. In this study, a longterm outcome of thrombolytic therapy was analysed and was found to be of clinical significance. Even though treatment of choice is percutaneous coronary intervention, thrombolysis has not lost its importance. (5)

Of the 120 cases in this observational study, 100 are still on followup after 15 years and of them 60 have survived without further complications on medical therapy and lifestyle modifications alone, 40 required coronary interventions in the form of PTCA or CABG. The diabetic patients were found to be having more risk for recurrent coronary events, more than that of hypertensives. $(6,7,8)$ Smoking as a risk factor was found in almost all of the male patients and had detrimental effect on outcome and recurrence of symptoms.(1,2) Dyslipidaemia, despite its presence as a significant comorbidity in relation to coronary artery disease, had less influence on the outcome of the study.(9) Strict adherence to medical therapy and lifestyle modifications had significant influence on better prognosis and longterm outcomes of coronary artery disease.

\section{CONCLUSION}

Coronary artery disease is a common cause of mortality and morbidity among population of developing countries. Thrombolysis as a treatment strategy for acute myocardial infarction is less popular now due to the advent of coronary interventional therapies. Despite the reduction in popularity, it is a very useful therapeutic modality in a resource-crunched rural setting, the likes of which are still prevalent in many places in the world. In regions where access to Cath Labs is difficult, thrombolysis can be life-saving in the immediate setting, and from our study, it has even got good longterm outcome. $20 \%$ of young smokers are doing fine after they quit smoking.

\section{REFERENCES}

[1] Steg PG, James SK, Atar D, et al. ESC guidelines for the management of acute myocardial infarction in patients presenting with S-T segment elevation. Eur Heart J 2012;33(20):2569-619.

[2] Xavier D, Pais P, Devereaux PJ, et al. Treatment and outcomes of acute coronary syndrome in India (CREATE): a prospective analysis of registry data. Lancet 2008;371(9622):1435-42.

[3] Noorani F, Runge M, Tripathi S, et al. Pre-hospital delays in care for STEMI patients in Mumbai: challenges and opportunities. Abstract 14400. Circulation 2016;134:A14400.

[4] Ramakrishnan S, Mishra S, Chakraborthy R, et al. The report on the Indian coronary intervention data for the year 2011-national interventional council. Indian Heart J 2013;65(5):518-21.

[5] Dalal JJ, Alexander T, Banerjee PS, et al. 2013 consensus statement for early reperfusion and pharmaco-invasive approach in patients presenting with chest pain diagnosed as STEMI (ST elevation myocardial infarction) in an Indian setting. J Assoc Physicians India 2014;62(6):473-83.

[6] Mohanan PP, Mathew R, Harikrishnan S, et al. Presentation, management and outcomes of 25748 acute coronary syndrome admissions in Kerala, India: results from Kerala ACS registry. Ear Heart J 2013;34(2):121-9.

[7] Armstrong PW, Gershlick AH, Goldstein P, et al. Fibrinolysis or primary PCI in ST-segment elevation myocardial infarction. $\mathrm{N}$ Engl J Med 2013;368(15):1379-87.

[8] Canon CP, Gibson CM, McCabe CH, et al. TNK-tissue plasminogen activator compared with front-loaded alteplase in acute myocardial infarction: results of TIMI $10 \mathrm{~B}$ trial. Thrombolysis in myocardial infarction (TIMI) 10B investigators. Circulation 1998;98(25):2805-14.

[9] Sathyamurthy I, Jayanthi K, Iyengar SS, et al. Efficacy and safety of tenecteplase in diabetic and non-diabetic patients of STEMI-Indian registry data. J Assoc Physicians India 2010;58:229-30. 